\title{
Cinema Sem Imagem: um caso de estudo de geração imagética
}

\author{
Filipe Lopes \\ INET-md, ESMAD, Portugal \\ Pedro M. Afonso \\ ESMAD, Portugal
}

\begin{abstract}
Cinema Without Image (CSI) is a sound creation exercise without visual support. It was purposely designed for cinema and audiovisual students, consequently, inspired and oriented by the audio workflow that usually makes up a film production. The authors believe that it is necessary to create pedagogical resources and experimental exercises which allows one to do creative sonic work, albeit led by a musical context and not sound design per se. This kind of context encompasses critical listening, sound manipulation practices, a phenomenological and empirical relationship with sound and, above all, a musical understanding of what one is producing and/ or listening. This paper will describe and analyze the CSI exercise based on contributions by the professor and the students but, specifically, the authors will try to understand the (musical) impact that the CSI had on the students.
\end{abstract}

Keywords: Sound, Music, Cinema, Education.

\section{Introdução}

É comum ouvir-se a expressão de que o som é cinquenta por cento da experiência do cinema. A ideia de analisar um filme pelo confinamento dos seus componentes parece-nos um pouco redutor, levando em conta que um filme é uma experiência "total". A relação do som com tudo resto é, antes de tudo, uma relação dinâmica, ora por vezes tomando a dianteira, ora por vezes remetendo-se "à sombra". Poderíamos dizer que o filme se desenrola numa espécie de dança entre os diferentes componentes ao ritmo da narrativa audiovisual, por vezes também chamada de storytelling, decorrendo daqui que qualquer divisão estanque é à partida errada. Ainda que a divisão e hierarquia operante seja útil no que diz respeito à organização de trabalho de uma equipa de cinema, i.e. produção de um filme, sobretudo no que diz respeito à gestão financeira, parece-nos que essa aura de rigidez, por vezes, acaba por resvalar para o trabalho criativo, prejudicando-o.

Ora, de regresso à primeira frase, dividir por percentagens cada parte que constitui um filme, mesmo que metaforicamente, é um erro porque transmite a ideia errada de que o cinema é apenas a soma de todas as partes. No caso particular do som, é uma força que ganha expressão na relação que estabelece com tudo o resto e, inegavelmente, é um trabalho criativo. $\mathrm{O}$ estatuto criativo que estamos a atribuir ao som, no entanto, teve de ser conquistado $e$ nem sempre é usado em toda a sua força expressiva, o que pode espelhar um desconhecimento dessa faceta do som pelos seus intervenientes. Não se trata de endeusar o som por si só, mas sim explorar de que forma o som pode favorecer toda a narrativa e demais componentes. Uma das razões que pode ter atrofiado o papel criativo do som no cinema deverá ter a ver com o seu início atribulado e difícil, levando em conta os esforços tecnológicos que foram necessários inventar. Essa dificuldade poderá ter minado a atração de músicos e compositores para o cinema em formatos que não fossem apenas os das bandas sonoras. Por outro lado, a obsessão pelo sincronismo, simbolizada pelo entusiasmo à volta dos talkies, poderá ter feito o som refém da imagem. Este pequeno preâmbulo leva-nos ao assunto genérico deste artigo: a criação sonora no cinema.

Não é nosso intuito indagar a fundo pelas relações do som com a imagem, o que nos levaria ao pensamento de autores importantes como Sergei Eisenstein, Michel Chion, Claudia Gorbman ou Walter Murch, mas sim tomar como axioma que o som e imagem têm uma relação expressiva que é dinâmica. A partir desse pressuposto, e em particular a partir da curta-metragem documental "Railway Station" (1980) do realizador Krzysztof Kieślowski, iremos explorar, por um lado, o trabalho musical não composicional (i.e. todo o som que não é banda sonora) e, por outro lado, relatar um estudo de caso, i.e. Cinema Sem Imagem (CSI), acerca de educação musical para estudantes de cinema. Este último ponto, i.e. educação musical, é o ponto principal deste artigo e objeto da nossa reflexão.

\section{Som=Música=Som}

Por alturas em que áudio e cinema começavam a cruzar caminhos e caminhar lado a lado, dava-se uma revolução musical pela Europa que, de resto, haveria de contaminar todo o mundo. Se, até ao final do séc. XIX, a música tonal reinava de forma relativamente incontestável, tomada como a (verdadeira) Música, adivinhava-se nas suas próprias metamorfoses ao longo da história que esse estatuto não iria durar para sempre. Se na música de Wagner a tonalidade já se esticava aos limites, e.g. Tristão e Isolda (1865), com Schonberg a música tonal conheceu uma transformação tão grande que levou ao seu próprio desmoronamento (Grout e Palisca, 1997). A composição musical sem hierarquia de notas, i.e. composição dodecafónica, é mais um sintoma de um conjunto de transformações violentas que transformou de forma indelével a música. Luigi Russolo, à boleia do movimento futurista do início do séc. $X X$, reclamou por uma música nova com base no ruído omnipresente das sociedades contemporâneas, e.g. 
maquinarias, guerra; Pierre Schafer, nos anos 40 e 50 , dá início à música concreta através da gravação de sons e posterior montagem e manipulação áudio dos "objetos sonoros"; Murray Schafer e John Cage, na $2^{\mathrm{a}}$ metade do séc. $X X$, inspirados e inspirando movimentos artísticos como o fluxus, chamam a atenção para a paisagem sonora, para a música que, afinal de contas, temos à nossa volta (Lopes, 2016). Estes são só alguns exemplos entre muitos outros. A música deixou de pertencer apenas aos músicos e ser tomada como uma coisa encerrada e venerada nas partituras, explodindo em todas as direções de tal forma que qualquer som ou sonoridade podia também ser música, tal como o eram até então os sons de um violoncelo ou uma partitura de Mozart. Esta cadência de acontecimentos esbateu a diferença entre som e música que, até ao início do séc. $X X$, parecia ser evidente. Hoje em dia ainda é comum diferenciar-se som e música, mas estamos em crer que a razão de isso acontecer é puramente semântica, por forma a que a comunicação por via da linguagem seja eficiente. Independentemente da conotação semântica, a verdade é que o som acontece quando chega ao corpo e aos ouvidos de alguém, o que implica que a escuta é também parte implicada neste processo. A escuta torna-se então parte integrante da relação que estabelecemos com o cinema e o som no cinema, decorrendo daqui também que a educação auditiva deve ser contemplada de forma estrutural no currículo audiovisual. A construção de ideias musicais sejam elas quais forem, inclusivamente aquelas que envolvem sons diegéticos no decorrer de um filme, implicam sempre um reconhecimento e educação auditiva sensível, ou seja, a escuta que ultrapassa o instinto de sobrevivência e a comunicação do dia a dia, mas que tem a ver com sensibilidade e afloramento estético. No filme Cast Away (2001), do realizador Robert Zemeckis, uma das cenas contempla a chegada de Tom Hanks a um gabinete onde está a Helen Hunt. Nesse gabinete vê-se uma fotocopiadora a trabalhar e é ao som da fotocopiadora que os atores começam a dançar, embalados pelo ritmo regular e musicalidade do som que emana da fotocopiadora. Esta eventualidade não foi fruto do acaso, mas uma escolha deliberada, tal como nos confirma o designer de som Randy Thom (Thom, 2020).

Conclui-se, portanto, que a música não é dependente do fenómeno (instrumento, partitura) mas, como se infere, é preciso reconhecer essa musicalidade (ouvinte) como também saber criar essa musicalidade (criador). No capítulo seguinte abordaremos a curta-metragem Railway Station (1980) do realizador Krzysztof Kieślowski, focando a nossa análise naquilo que são as sonoridades musicais não composicionais, ou seja, a musicalidade dos sons diegéticos, meta-diegéticos e a montagem/ organização dos mesmos.

\section{Railway Station}

Não é nosso intuito fazer uma análise exaustiva do trabalho de Kieślowski mas antes apoiarmo-nos na sua curta-metragem documental "Railway Station" (1980) para relatar uma ideia de musicalidade e, consequentemente, um trabalho sonoro em cinema que não usando banda sonora é intimamente musical. A escolha desta curta-metragem é um feliz acaso, ou seja, nas diversas análises que fizemos e pesquisamos na literatura, acabamos por ser conduzidos a esta obra que nos pareceu exemplificativa do que procurávamos. Railway Station retrata a vida das pessoas numa estação de comboios na Polónia. É-nos transmitida uma ideia de um espaço carregado de gente frustrada e deambulante onde pouca coisa funciona corretamente. Contudo, essa confusão humana e burocrática é contrabalançada pelas fiéis câmaras de vigilância que, contrariamente aos horários de chegada e partida dos comboios, registam e funcionam com precisão. Uma análise ao som permite-nos debater alguns aspetos que nos parecem musicais no sentido clássico, i.e. da teoria musical, mas também narrativo, i.e. forma.

Comecemos, pois, pelo início. No princípio da curta-metragem é-nos dada a ouvir uma voz que parece vir dos grandes ecrãs na estação, porém, a sequência de planos seguintes que nos levam a diferentes espaços da estação, parece não afetar o timbre e reverberação dessa mesma voz, já que o timbre desta permanece inalterada. Do ponto de vista acústico, ou seja, da perceção do som pelas pessoas, faria sentido que nos diferentes espaços essa voz se ouvisse com reverberações e timbres diferentes, mas não é isso que acontece, apenas mudam as paisagens sonoras (i.e. passos, vozes) que embalam essa voz. A não alteração acústica e a grande reverberação parecem sugerir que se trata de uma voz "angelical", o que nos deixa em dúvida se se trata de um som diegético ou se, ao mesmo tempo, se se trata de uma voz onírica e simbólica, i.e. som meta-diegético, do estado de espirito das pessoas. Esta dúvida é ainda mais realçada pelo facto de o texto ser propagandístico e ser preferido com uma cadência rítmica bastante acelerada. Esta introdução é abruptamente finalizada por uma outra voz que anuncia a chegada de um comboio. Essa interrupção imprevista, parece-nos, assemelha-se ao acordar de um sonho; segue-se uma sequência de imagens acompanhadas por paisagens sonoras, mantendo-se um volume de som intenso, que culminam na primeira filmagem da câmara de vigilância e do seu respetivo leitmotiv, ou seja, um motivo musical recorrente que se associa a uma personagem/ objeto. Esta estratégia, originária na ópera e hoje dia perfeitamente comum no cinema, como exemplificado no filme $M$ de Fritz Lang (Crabbe, 2016) repete-se ao longo da curta-metragem. Além do motivo com os tímpanos, referente às câmaras de vigilância, temos o leitmotiv do piano que está associado às pessoas, à espera e ao deambular. Chamamos a atenção para o facto do tímpano, associado às câmaras de vigilância, ser um som percussivo e o tipo de ritmo tocado ter um carácter militar, o que não surpreende tendo em conta o texto proferido no início da curta e toda a trama do filme; O som do piano, em claro contraste, tem um tom simplista mas polvilhado por delays que the 
atribuem um certo sentido onírico, algo que também nos parece estar ligado à influência meta-diegética da voz inicial. Numa das cenas a meio da curta, as pessoas perguntam quanto custa o bilhete e, durante alguns segundos, assistimos à mesma frase repetida três vezes: "quanto é?". A repetição de um som é um recurso emblemático da música concreta que parece-nos encontrar aqui uma certa ressonância. A repetição não só enfatiza o texto e a mensagem, como também nos permite descobrir novos aspetos no som que à primeira audição passam despercebidos. A teoria da música concreta assim como a psicoacústica explicam bem este fenómeno; seguem-se sequências de imagens que oscilam entre volume intenso e delicado, dando-se primazia aos sons de vozes e conversas, sempre intercalados pelos leitmotivs. Ao aproximarmo-nos do final da curta, é anunciada a apresentação de um filme nos grandes ecrãs e o leitmotiv do piano parece-nos que é aqui desenvolvido. Ouve-se uma grande frase de um piano reverberado que, posteriormente, irá desembocar no som da sala onde se encontra o segurança a olhar para as pessoas através das câmaras de vigilância. Por último, é interessante notar que em termos de forma, mesmo que seja uma dedução um pouco otimista, parece-nos que se trata de um A B A, uma forma muito popular na música erudita, ou seja, o início da curta (i.e. televisão, discurso e reverberação) é semelhante ao final e pelo meio ouvem-se coisas completamente diferentes.

Em suma, estamos em crer que tanto no que diz respeito aos sons em si, como também ao seu tratamento, montagem e articulação, ouvimos uma composição musical. Como seria de esperar, trata-se de uma composição musical que encontra a sua plenitude na junção com a parte visual, ainda assim, uma faixa sonora profundamente musical. Ora, se no cinema existem abordagens musicais ao som independentes da banda sonora, tal como a que descrevemos, perguntamo-nos como é que se educa em contexto académico esse tipo de sentido musical?

\section{Cinema Sem Imagem}

O Cinema Sem Imagem foi um exercício de criação sonora sem suporte visual, concretizado numa performance ao vivo na qual o público estava com os olhos vendados. Pretendia-se criar algo que fosse capaz de gerar imagens a partir de sonoridades forjadas em tempo real. Estas, por sua vez, deveriam integrar os diversos contributos individuais que, por sua vez, ajudariam a criar uma narrativa sonora coletiva. Sendo intencionalmente proposto a alunos do curso de cinema e audiovisual, foi inspirado e orientado para o trabalho áudio que normalmente se desenvolve numa produção cinematográfica. As técnicas usadas durante o processo criativo derivam das práticas comuns da indústria cinematográfica (i.e. foley, voz-off, ambientes, paisagens sonoras), providenciando contato in loco com as técnicas e o seu potencial criativo. Concretamente, a proposta consistiu na criação de grupos entre os estudantes que, por sua vez, ficaram encarregues de idealizar sonoramente uma parte de um conto previamente escolhido. Cada grupo, além da sua sonorização respetiva, ficaria também distribuído em uma das seguintes categorias áudio: foley, diálogo, paisagem sonora, efeitos sonoros, música, difusão e espacialização e, finalmente, registo. Isto quer então dizer que cada grupo é uma espécie de naipe de uma orquestra e, ao mesmo tempo, compositor de um trecho do conto. Em termos práticos, se eu pertencer ao grupo das pessoas que ficam no naipe das paisagens sonora, não só vou "tocar" paisagens sonoras na parte do conto que o meu grupo idealizou e sonorizou, como também vou "tocar" nas restantes partes do conto de acordo com as indicações que os outros grupos me deram para as partes que idealizaram e sonorizaram. Em suma, o CSI originou uma performance sonora contínua que retratava um conto apenas com som. O público foi rodeado pelos estudantes e estava vendado para que a experiência acusmática fosse melhor enfatizada.

Aestrutura um tanto rígida do exercício é balanceada pela natureza criativa e reflexiva inerente da visão e participação dos alunos. Assumindo que o trabalho de som em cinema não se reduz aos aspetos técnicos ou simples implementação técnica para suportar os conceitos visuais, é necessário criar contextos pedagógicos e experimentais de trabalho criativo com som que estimulem a escuta crítica, a manipulação e produção de som e um vínculo fenomenológico e empírico com o som. Seguir-se-á a análise do CSI a partir de contributos do docente e estudantes, almejando-se desta análise um entendimento sobre a repercussão que o CSI teve nos estudantes, o processo de conceptualização e prático, mas também pensar como criar contextos de educação musical e auditiva pertinentes para estudantes de cinema.

\section{Metodologia}

Nenhum exercício didático se concretiza e vive apenas da teoria. Pensados e feitos para ensinar, suscitar, provocar, estes apenas se concretizam na pessoa que é parte integrante do processo, no recetor, no discente. Como tal, para além da reflexão teórica que o exercício merece, quer seja na fase de desenvolvimento, quer seja na fase de análise, existe uma dimensão que se estende para além do docente e que deve ser procurada para obtenção de feedback dos intervenientes. Para esta exploração, um questionário de 6 perguntas de resposta aberta foi desenvolvido na ferramenta Google Forms. Esta abordagem foi escolhida uma vez que não interessava uma análise quantitativa do processo, dificilmente balizada em escalas alfanuméricas, mas sim uma perspetiva holística da experiência dos intervenientes, abrindo espaço para a descrição de reflexões pessoais que nos informassem acerca do processo de preparação, execução e análise da performance individual e de grupo durante todo o projeto. Cada questão associa-se a uma "variável" de interesse de estudo. O uso das aspas não é inocente: não poderemos olhar para estas respostas e para a análise destes resultados de um ponto de vista quantitativo e estanque. As perguntas 
versam sobre objetivos de estudo planeados, mas será necessário ser conservador na perspetiva de obtenção de resultados uniformes e que versem sobre o objetivo em cada resposta.

Tabela 1 - Perguntas de Investigação

\section{Formulação da Questão}

Descreva sucintamente o seu papel no exercício CSI.

\section{"Variáveis" de Estudo}

Caracterização do participante para enquadramento das respostas seguintes; Avaliação da interpretação do papel de cada elemento no exercício

Que processos criativos utilizou para o desenvolvimento e concretização do CSI?

Como descreve a sua experiência durante o exercício CSI?

O exercício CSI surtiu algum impacto em si, no que diz respeito à sua relação pessoal com o Som? Se sim, comente esse impacto.

Após a sua experiência com o exercício CSI, tem algum tipo de sugestão que possa fornecer para edições futuras?

\section{Deseja acrescentar algum comentário?}

Análise do engagement e do grau de preparação para o exercício

Avaliação da experiência do discente; Avaliação das análises dos discentes ao decorrer do exercício em si

Análise dos elementos didáticos apreendidos durante 0 exercício; Avaliação do impacto na perceção individual do Som

Procura de feedback dos intervenientes para melhorias no processo didático

Avaliação de potenciais lacunas de conteúdo criadas pelas questões anteriores
O formulário foi construído de forma a preservar o anonimato dos participantes e a não influenciar as respostas e o feedback fornecidos pelos intervenientes. Após a recolha dos dados, estes foram avaliados de um ponto de vista qualitativo, de forma a extrair os dados relevantes para discussão do exercício.

\section{Discussão}

Foram obtidos 9 questionários totalmente preenchidos, a partir dos quais foi feita a análise da perspetiva dos discentes participantes. Será de mencionar que este se tratou de um valor francamente abaixo do número total de participantes. As razões que motivaram tal desfasamento podem estar relacionadas pelos meios de divulgação do questionário, pelo nível de interesse dos alunos, pela distância temporal para o exercício (cerca de um ano), ou inclusivamente a situação atual de pandemia, mas resultam numa amostra abaixo do ideal. Tal não impede, contudo, a extração de conclusões significativas do questionário que informem acerca do exercício. Em primeira instância, será interessante verificar que a descrição dos papéis dos discentes responsáveis pelo mesmo grupo, i.e. foley, paisagem sonoras, efeitos sonoros. Estas descrições, podendo ser justificadas como pequenas variações linguísticas, tais como "locução" ao invés de "voz", ou "Ambientes" versus "MIDI", demonstram diferentes abordagens pessoais face ao papel que encaram. É, desde já, possível observar a destrinça entre abordagens mais aproximadas à técnica (Voz ou MIDI) e abordagens mais ligadas à componente conceptual (Locução e Ambientes), demonstrando diferentes organizações hierárquicas dentro dos próprios grupos, bem como um foco pessoal pretendido para o processo. Estas diferenças reforçam os objetivos iniciais traçados para o Exercício, permitindo uma abordagem livre por parte de cada aluno na construção da sua relação com o exercício e, em última instância, com a disciplina do Som. A análise à segunda questão traz algumas questões que devem ser abordadas com maior cautela e devem ser fruto de uma maior reflexão. A construção de processos criativos próprios na área do Audiovisual assume uma importância acrescida por se tratar de um meio tão alicerçado na expressão artística de cada um, mesmo nas componentes mais técnicas. Esta construção deve assentar em bases teóricas e análise de material pré-existente, não o utilizando como dogma de atuação, mas bebendo das influências do status quo e, se adequado, quebrando-o. As respostas obtidas demonstram que essa pesquisa de referências e abordagens não foi realizada, com uma preparação muito ad hoc e baseada nos exercícios de improviso que antecederam a avaliação final e visavam fortalecer as simbioses entre os vários grupos. A maioria das respostas menciona a leitura do conto a "musicar" como o processo de preparação mais relevante, demonstrando uma preocupação importante em fazer jus ao material de origem e em contextualizar todo o processo. Existiu, também, uma forte preocupação com a familiarização com o material a empregar no exercício, reforçando, novamente, o cuidado que foi tido com a técnica ao longo de todo o processo. Menos consistente foi a procura de "envolvimento" com os restantes grupos ao longo do processo de ensaios e preparação do Exercício. Esta componente de participação e adaptação face às valências de cada 
colega pareceu esbarrar nas procuras individuais pela execução adequada do seu grupo. É com esta base que se torna ainda mais relevante a análise e menção à resposta que a nossa amostra apresentou relativamente à experiência durante a execução do exercício. Não só os discentes relataram a experiência como "interessante" e "agradável", como também apontaram a imersão criada pela "simbiose" entre todos os grupos como sendo algo de positivo. A própria relação com o Som, elemento a avaliar na questão seguinte, bem como alguns aspetos a melhorar, começavam já a ser indiciados, fazendo-nos crer que a experiência, mais do que a análise teórica dos elementos que compunham o exercício, fornece uma visão mais abrangente e informada acerca dos verdadeiros efeitos do Exercício. Na senda das respostas à questão anterior, a uniformidade nas respostas à quarta questão, que versava sobre o impacto do exercício na relação pessoal com o Som, validam o intuito inicial do Exercício e reforçam a sua relevância enquanto instrumento pedagógico. Todos os inquiridos mencionaram uma alteração na sua abordagem e perceção da disciplina sonora no meio audiovisual, com a maioria dos discentes a realçar a capacidade do Som enquanto ferramenta imersiva e criadora de emoções e imagens mentais. Estas respostas demonstram uma certa prerrogativa do Som que, no Audiovisual, teima em ser percecionado como um veículo adicional à Imagem, de complemento e servidão, incapaz de se emancipar e transportar, em si mesmo, as emoções e poder imaginativo que são comumente atribuídos à Imagem. Em menor grau, foram também mencionadas evoluções ao nível técnico e de compreensão das subdisciplinas do Som, essenciais para a construção de um todo uniforme e coeso. Contudo, não será demais reforçar que esta questão, talvez a mais importante de toda esta investigação e que suporta o racional pedagógico por detrás do projeto, demonstra um paradigma ainda muito "visual" embutido nos discentes, algo que deve continuar a ser combatido por este tipo de exercícios. O feedback fornecido pelos alunos inquiridos incide num dos problemas que permeou, também, a realização deste estudo: a falta de comunicação entre os elementos. A verdade é que, se por um lado o engagement dos alunos durante o processo de avaliação se demonstrou evidente, a sua preparação e comunicação nas fases de ensaio e de reflexão demonstraram-se limitadas e um dos pontos a incidir em edições futuras deste Exercício. É, obviamente, um processo complexo e que depende sempre da vontade dos alunos em investir tempo e dedicação em projetos de avaliação que não são, muitas das vezes, as prioridades letivas nem em termos de interesse. No entanto, seria de esperar uma maior comunicação entre os vários elementos, algo que parece apenas ter surgido durante os momentos de ensaio em conjunto, realizados em aula. Adicionalmente, foi também reforçada a necessidade de fornecer mais tempo e oportunidades de ensaio para que a turma se pudesse articular de uma forma mais eficaz e obter um resultado final ainda mais interessante. Por fim, de mencionar que um dos comentários mencionou a possibilidade de retirar a componente textual, de narração, do Exercício, tornando-o apenas sonoro. Esta abordagem poderá ser utilizada em Exercícios futuros e demonstra a vivacidade das imagens que o Som provocou nos intervenientes.

\section{Na primeira pessoa: discente}

A posição enquanto discente permite, como já mencionado, um acesso privilegiado aos meandros da concretização de um exercício que é sustentado pelos alunos. A reflexão acerca do tema ganha, por isso, contornos pedagógicos distintos daquela que um docente poderá e deverá retirar da concretização do Exercício. É importante mencionar, em primeira instância, que o engagement dos alunos e a sua dedicação têm a palavra quanto ao sucesso do exercício. E este engagement não se pode controlar apenas com aulas atrativas e liberdade de exploração: pressupõe uma dedicação extra por parte dos alunos em busca de uma simbiose que ultrapasse os normais problemas de comunicação. Será importante, por isso, desmistificar a ideia de que o Docente é o maior responsável pela concretização de um exercício com sucesso e que as avaliações que daí advém são consequência direta da postura e abordagens que este assume. Por outro lado, uma constatação que parece ir contra a "lógica", mas que é fortemente apoiada pela evidência empírica, consiste na evidência de que um maior grau de liberdade conferido aos alunos traz desconforto e um refúgio em papéis "secundários" que não coloquem em evidência a necessidade de debater e dialogar para concretizar o projeto. É nesta fuga à comunicação, nesta vontade de refúgio, que a participação perde força coletiva e o projeto se torna mais um projeto de um grupo restrito de alunos motivados para o mesmo, com executantes que se alicerçam nas bases que os primeiros lançam. Obviamente que tal acontece em todos os processos educativos, não se trata de um fenómeno inédito associado a uma metodologia de estudo mais livre. Mas é, sem dúvida, acentuado por esta mesma metodologia e deve ser um motivo de análise para edições futuras. Em termos de preparação, é evidente que, quanto mais tempo for disponibilizado em aula para os ensaios, melhores serão os resultados. No entanto, o trabalho não deve limitar-se a estes momentos de contacto, podendo e devendo ser adotadas estratégias que permitam uma colaboração à distância. Para além disso, a ausência de uma figura hierárquica superior, como um maestro, que "imponha" limites poderá ajudar ao foco e uma maior concentração no projeto. Em termos conceptuais, o exercício funciona em toda a linha: suscita imagens, sensibiliza os alunos, arrasta-nos para um Mundo de composição sonora que transcende o cânone imagético em vigor. É um exercício de composição abstrata, obriga os alunos a trabalhar as sinergias, obriga a sentir, respeitar o espaço e os momentos de intervenção de cada um. É Arte comunitária e participativa. E é, sem dúvida, um caminho que vale a pena trilhar. 


\section{Na primeira pessoa: docente}

Há obviamente uma visão enviesada da minha parte, enquanto docente, de que a musicalidade é importante. O meu percurso como músico, performer e compositor, transborda inevitavelmente para a minha forma de pensar o som no cinema. Ainda assim, tal como vemos em autores como Michel Chion ou em designers de som como Walter Murch, a musicalidade e o poder narrativo do som em parceria com a imagem é evidente. Ao estabelecer uma relação de simbiose entre o visual e o auditivo, eleva-se o sentido poético da experiência audiovisual. Ora, quando pensei no CSI, pensei em criar um contexto híbrido que pudesse ir beber à performance musical, mas também ao trabalho áudio vulgar na produção de um filme. Era importante colocar o grupo de estudantes numa posição que se tivesse de confrontar com aspetos musicais, estranhos à maioria, mas também que os pudessem metamorfosear num "espaço" que fosse seu e do cinema. Acima de tudo, queria colocar o grupo numa posição que os convidasse a ouvir o seu trabalho individual e coletivo como música, apreciando as variações dinâmicas, melodias, timbres, conjugação de sons, ritmo, forma, enfim, tudo aquilo que caracteriza o trabalho convencional da composição musical. Ao contrário de um músico, que está sobretudo concentrado no seu instrumento mas escutando os outros, queria trazer para o CSI uma forma de estar mais próxima da composição musical, ou seja, uma situação que convide os intervenientes não só a pensar no seu som e na escuta dos outros, mas também que instigue a criação de relações em tempo real com todas as outras facetas sonoras que ajudam à criação do sentido musical e, dessa forma, da expressividade sonora. O CSI está ainda distante de atingir os resultados que imaginei, no entanto, a composição criada e a performance que experienciei, deu-me a sensação de caminhar no sentido correto, de tal forma que num ou noutro momento deixei de "ouvir cinema" e passei a escutar música. O caminho continuará.

\section{Conclusão}

Tomando como base a reflexão realizada feita na Introdução desta Comunicação, o exercício CSI permitiu-nos validar a hipótese de que, efetivamente, grande parte dos alunos de cinema e audiovisual subestimam e se refugiam dos "meandros" do Som, relegando-o para segundo plano numa construção que é simbiótica em partes não-mensuráveis. O exercício CSI está longe de ser um objeto estanque e aprimorado: apresenta-se ainda como um protótipo, um móbil, que se movimenta de acordo com a maior ou menor força, interesse e dedicação que os alunos nele aplicam. Contudo, esta primeira experiência permitiu-nos tirar ilações que fundamentarão futuros desenvolvimentos. Será necessário um maior trabalho de estimulação de escuta ativa e pensamento sonoro criativo, em disciplinas prévias e trabalhos suplementares, conferir uma figura de maestro que permita chegar a um consenso com maior facilidade e unifique a obra, bem como uma procura de mais engajamento por parte dos alunos na criação, ao invés do foco excessivo na técnica. O exercício parece-nos, no entanto, como uma base de uma ferramenta pedagógica sólida, permitindo abrir horizontes de alunos que ainda possam aderir em demasia ao cânone visual do Audiovisual e estimular a criatividade em alunos com uma compreensão mais holística e integrativa das diversas disciplinas do Cinema. As respostas dos alunos, as experiências dos autores deste artigo e a resposta do público atestam esse potencial e o espaço de melhoria. Salvaguarda-se, no entanto, a necessidade de que o esforço exigido pelo trabalho sonoro seja acompanhado de uma sensibilização devida para o papel do Som noutras Unidades Curriculares que tratem da construção do Mundo Cinematográfico. Não se trata apenas de construir isoladamente ou a posteriori um contexto sonoro que exacerbe, amplifique ou complemente a imagem; trata-se, sim, de um processo em fluxo que deve ser tido em conta desde a conceção do projeto, i.e. escrita do argumento, até às opções na sala de montagem. Urge uma reflexão do atual cânone de criação audiovisual, uma busca de uma síntese de dois "opostos" que apenas o são por convenções previamente estabelecidas com base em preceitos históricos obviamente limitados e errados.

\section{Bibliografia}

Crabbe, Eoghan. 2016. Fritz Lang's M And The Use Of Sound. https://www.filminquiry.com/fritz-langs-m-and-theuse-of-sound/. Acedido em 17 de abril de 2020.

Grout, Donald J., e Claude Palisca. 1997. "História da música ocidental.”. Lisboa, Gradiva

Lopes, Filipe. 2016. Composição musical com o espaço. Tese de Doutoramento, Faculdade de Engenharia da Universidade do Porto.

Thom, Randy. 2020. Randy Thom explains Cast Away's naturalistic sound. https://www.youtube.com/watch?v=1_ BUMZBUw70. Acedido em 20 de abril de 2020.

\section{Filmografia}

Cast Away, 2000. De Robert Zemeckis. EUA: Twentieth Century Fox. DVD.

Dworzec, 1980. De Krzysztof Kieślowski. Polónia: WFD. Vídeo online.

Trois Couleurs: Blanc. 1994. De Krzysztof Kieślowski. Portugal: Leopardo Filmes. DVD

Trois Couleurs: Bleu. 1993. De Krzysztof Kieślowski. Portugal: Leopardo Filmes. DVD

Trois Couleurs: Rouge. 1994. De Krzysztof Kieślowski. Portugal: Leopardo Filmes. DVD 